\title{
Formulation and Evaluation of Chitosan Nanospheres Containing Methotrexate Targeted Drug Delivery System
}

\author{
Sokkalingam Arumugam Dhanaraj ${ }^{1 *}$,Selvadurai Muralidharan ${ }^{2}$, Vijayan Venugopal $^{3}$, Puspavathy Kanniappan ${ }^{3}$, \\ Winnie Tan Sze Hui ${ }^{3}$, Lim Li Qi ${ }^{3}$ \\ ${ }^{1}$ Pharmaceutics, Faculty of Pharmacy, JSS University, Mysore, Karnataka, INDIA. \\ ${ }^{2}$ Pharmaceutical Chemistry Unit, Faculty of Pharmacy, AIMST University, Semeling, Bedong, MALAYSIA. \\ ${ }^{3}$ Pharmaceutical Technology Unit, Faculty of Pharmacy, AIMST University, Semeling, Bedong, MALAYSIA.
}

\begin{abstract}
Objective: The aim of the present study is to prepare and evaluate nanoparticles containing methotrexate using chitosan as the polymer. The MTX-loaded CS-NPs were prepared by the emulsion polymerization method using glutaraldehyde as the cross-linking agent. Methods: CS nanospheres prepared using $1.0 \% \mathrm{w} / \mathrm{v}$ chitosan gel (in $4.0 \% \mathrm{v} / \mathrm{v}$ glacial acetic acid), $2.5 \mathrm{mg}, 5.0 \mathrm{mg}$ and $10 \mathrm{mg}$ of MTX, $6.0 \mathrm{~mL}$ GST and $0.6 \mathrm{~mL}$ Span 80 yielded the most satisfactory product. Formulation was optimized and in vitro drug release was performed. In-vitro release study was done in HPLC water. Results: The MTX-loaded CS-NPs were formed by the emulsion polymerization method. The particle size, loading efficiency and in-vitro release varied from 779.9 to $3079.0 \mathrm{~nm}, 70.93$ to $82.68 \%$ and 10.29 to $84.67 \%$, respectively for the formulated sample. Release kinetics showed diffusion-controlled and Non-Fickian release pattern. The zeta potential of three formulations achieved optimum values between -16.8 to $23.3 \mathrm{mV}$. Optimum zeta potential is essential for the uniformity of the nanoparticles size distribution. CS-MTX has shown a sustained release pattern in vitro. Conclusion: The sample C (10.0 mg) showed the least particle size, optimum
\end{abstract}

zeta potential range, moderate drug loading efficiency followed by sustained drug release over 48 hours. Hence, this formulation satisfactorily maintain the bioavailability and targeting efficiency towards cancer cell. Thus, the nano-formulation has a potential to be a sustained release, passive targeted delivery system for MTX, with reduced side effects associated with the drug.

Key words: Methotrexate, Chitosan, Nanopacticle, HPLC, Targeted drug delivery system.

Correspondence :

Dr Sokkalingam Arumugam Dhanaraj,

Dean, Global Engagement, College of Pharmacy, JSS University, Mysore, Karnataka, INDIA.

Phone no: +919626136114

E-mail: dhansooty@hotmail.com

DOI: 10.5530/jyp.2016.4.7

\section{INTRODUCTION}

Controlled drug delivery systems offer numerous advantages over conventional dosages forms, including improved efficacy, reduce toxicity, and improved patient compliance, and can be utilized in the form of nanocarriers in drug delivery. ${ }^{1}$ Nanoparticles are solid colloidal particles with diameters ranging from 1-1000 nm. ${ }^{2}$ They consist of macromolecular materials in which the active ingredient is dissolved, entrapped, encapsulated, adsorbed or chemically attached. ${ }^{3}$ They may be prepared from a variety of materials such as proteins, polysaccharides and synthetic polymers. The selection of materials is dependent on many factors including: (a) size of nanoparticles required; (b) inherent properties of the drug, e.g., solubility and stability; (c) surface characteristics such as charge and permeability; (d) degree of biodegradability, biocompatibility and toxicity; and (e) drug release profile desired. ${ }^{4}$ Chemically methotrexate is $\mathrm{N}$-[4[[(2,4-diamino-6-pteridinyl) methyl] methyl-amino] benzoyl]-L-glutamic acid. Methotraxate is an antineoplastic antimetabolite with immunosuppressant properties and used in the treatment of certain neoplastic diseases, severe psoriasis, and adult rheumatoid arthritis. ${ }^{5}$ Methotrexate irreversibly binds to and inhibits dihydrofolate reductase, inhibiting the formation of reduced folates, and thymidylate synthetase, resulting in inhibition of purine and thymidylic acid synthesis, thus interfering with DNA synthesis, repair, and cellular replication. Methotrexate is cell cycle specific for the S phase of the cycle. ${ }^{6}$ Targeted drug delivery is a method of delivering medication to a patient in a manner that increases the concentration of the medication in some parts of the body relative to others. Targeted drug delivery seeks to concentrate the medication in the tissues of interest while reducing the relative concentration of the medication in the remaining tissues. This improves efficacy of the while reducing side effects. ${ }^{7}$ The loading of drugs into ultrafine colloidal capsule in the nanometer size range (10 to $1000 \mathrm{~nm}$ ) is technique for the optimization of drug delivery to the desired site with the drug encapsulated, dissolved, adsorbed, or covalently attached. These colloidal capsules are termed as nanoparticles. ${ }^{8}$ They can entrap drugs in a stable and reproducible fashion with presence of stabilizers such as dextran and its derivatives by a process of polymer grafting to modify the characteristics of the nanoparticle surface charges and surface behavior, thus the drugs can either be directly incorporated during the polymerization process or by adsorption onto preformed nanoparticles. ${ }^{9}$ The primary goals of nanoparticles in drug delivery include more specific drug targeting and delivery, reduction in toxicity while maintaining therapeutic effects, greater safety and biocompatibility, and faster development of new safe medicines. ${ }^{10}$ Grenha et al described a method used to form chitosan nanoparticles and involves the preparation of a W/O emulsion (this first report described the emulsification of chitosan aqueous solution in toluene, using Span $80^{\circ}$ as emulsifier), with subsequent addition of a cross-linking agent that has the function of hardening the formed droplets. The reactive amino groups of chitosan undergo a covalent crosslinking with the aldehyde groups of glutaraldehyde which is added after the emulsion formation and consequently, after nanoparticle production. ${ }^{11}$ An isocratic high-pressure liquid chromatography (HPLC) method was developed to quantity Methotrexate. In vitro drug release study suggests sustain drug release for longer period of time. The synthesized nanoparticles have spherical shape with sizes range $779.9 \mathrm{~nm}$ to $3079.0 \mathrm{~nm}$. The percentage entrapment efficiency was $70.93 \%$ to $82.68 \%$. The developed systems were characterized for size, shape, zeta-potential, entrapment efficiency and In-vitro release. 


\section{MATERIALS AND METHODS}

\section{Materials}

Methotrexate was purchased from sunpharma India. chitosan (150 cps) was obtained from Central Marine Fisheries Research Institute Cochin, India. Sodium chloride was purchased from Unilab. 3\% Glacial Acetic Acid, Toluene and Span 80 were purchased from Quicklab Sdn. Bhd. $25 \%$ aqueous Glutaraldehyde solution was supplied from Plant Succeed. Linseed oil was from Medina Jaya Sdn. Bhd. Acetone was purchased from Merck.

\section{Preparation of $1.0 \%$ w/v of 150 cps chitosan Gel}

150 cps chitosan and sodium chloride were dissolved in 3\% glacial acetic acid and stirred with slight warming. Then, the solution was kept overnight for air drying under room temperature to obtain a clear gel of $1.0 \% \mathrm{w} / \mathrm{v}$ of 150 cps chitosan.

\section{Preparation of Glutaraldehyde Saturated Toluene (GST)}

Glutaraldehyde and $7 \mathrm{~mL}$ Toluene were mixed well for 30 minutes and then it was shaken vigorously. The solution was left overnight for saturation and separation.

\section{Preparation of nanospheres without drug incorporation}

The $1 \%$ w/v chitosan gel was added with acetone dropwise with stirring. Polymer gel was added drop wise into linseed oil and allowed to emulsify under magnetic stirring at room temperature for one hour. Polymer was precipitated to the evaporation of acetone with subsequent formation of smaller spheres suspended in the oil phase. GST with Span 80 was added drop wise to the emulsion and it was continued stirring for 4 hours. The emulsion was centrifuged at $4800 \mathrm{rpm}$ for 20 minutes. The supernatant was discarded and fresh toluene was added and centrifuged at $4800 \mathrm{rpm}$ for 20 minutes. The centrifugation was repeated for 5 times. Acetone was added, mixed well and centrifuged at $4800 \mathrm{rpm}$ for 10 minutes and repeated for 2 times. The content was dried in the incubator in glass petri plate. Powders were observed under 40X microscope.

\section{Preparation of drug loaded nanospheres with $1.0 \% \mathrm{w} / \mathrm{v}$ 150 cps chitosan}

Three batches of $1.0 \% \mathrm{w} / \mathrm{v}$ of $150 \mathrm{cps}$ chitosan gel were prepared with different concentration of methotrexate, which are $2.5 \mathrm{mg}, 5.0 \mathrm{mg}$ and $10.0 \mathrm{mg}$. The emulsions were stirred stirrer for 1 hour then kept on standing for another 1 hour.

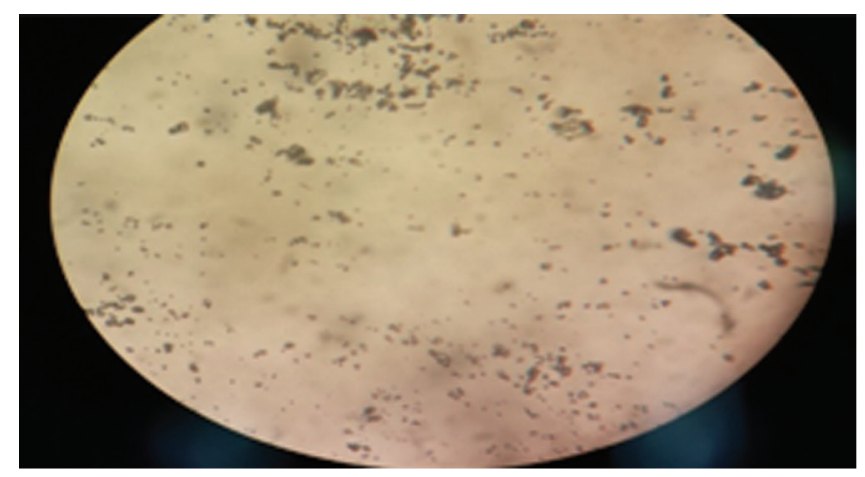

(A) Chitosan nanospheres under microscope 40X

\section{Preparation of methotrexate-loaded nanospheres}

For the preparation of methotrexate-loaded nanospheres, firstly, acetone was added dropwise into beakers containing $1 \% \mathrm{w} / \mathrm{v}$ of $150 \mathrm{cps}$ chitosan gel prepared with different methotrexate concentrations in the ratio of 1:1. Then the polymer gel was added in dropwise into linseed oil and was allowed to emulsify under magnetic stirring. Polymer was precipitated to the evaporation of acetone with subsequent formation of smaller spheres suspended in the oil phase. GST layer was separated and the Toluene layer which had prepared was mixed with Span 80. GST with Span 80 was added dropwise to the emulsion and it was continued stirring under magnetic stirrer. The emulsions in each beaker were centrifuged at 4800 rpm and the upper oily supernatant was discarded. Toluene was added into each tube and shaken vigorously. The tubes were centrifuged at 4800 rpm and the supernatant was discarded. This step was repeated a few times and after that, acetone was added, mixed well and centrifuged at $4800 \mathrm{rpm}$. After centrifugation, acetone was added into each test tube and the mixture was mixed well. Upon drying, brown coloured and free flowing of fine powder was obtained. Powders were observed under 40X microscope (Figure 1).

\section{Calibration curve}

For the preparation of calibration curve, $1 \mathrm{mg} / \mathrm{ml}$ of methotrexate stock solution was prepared. Then the stock solution was used to prepare methotrexate concentrations of $200 \mathrm{ng} / \mathrm{ml}, 400 \mathrm{ng} / \mathrm{ml}, 600 \mathrm{ng} / \mathrm{ml}, 800$ $\mathrm{ng} / \mathrm{ml}, 1000 \mathrm{ng} / \mathrm{ml}$ and $1500 \mathrm{ng} / \mathrm{ml}$ by using serial dilution with deionized water. Standard solution was analyzed using HPLC and standard curve was plotted by taking the peak area at $y$-axis a concentration $(\mathrm{ng} / \mathrm{ml})$ at $\mathrm{X}$-axis (Table 1$)$.

\section{Optimization method of HPLC analysis}

Chromatographic separation was performed on a Shimadzu liquid chromatographic system equipped with a LC-20AD solvent delivery system (pump), SPD M 10AVP photo diode array detector, Rheodyne $7725 \mathrm{i}$ injector with $25 \mu \mathrm{l}$ loop volume. Class-VP 6.01 data station was applied for data collecting and processing (Shimadzu, Japan). A Phenomenex Gemini C column (250 mmx $4.6 \mathrm{~mm}$ i.d., $5 \mu$ ) was used for the separation, mobile phase of a mixture of acetonitrile $(\mathrm{pH} 2.8)$ and $0.5 \%$ triethylamine ( $\mathrm{pH} 3.5$ adjusted with orthophosphoric acid); (50:50 $\mathrm{v} / \mathrm{v}$ ) was delivered at a flow rate of $1.0 \mathrm{ml} / \mathrm{min}$ with detection at $480 \mathrm{~nm}$. The mobile phase was filtered through a $0.2 \mu$ membrane filter and degassed. The injection volume was $25 \mu \mathrm{l}$ and the analysis was performed at ambient temperature (Figure 2).

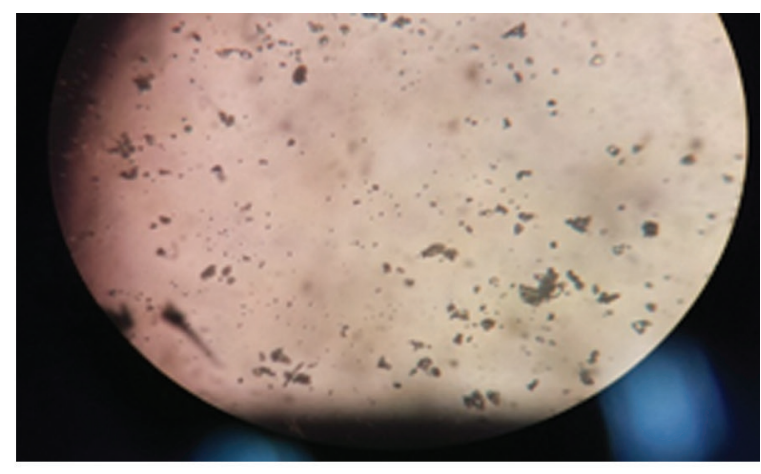

(B) Drug-loaded chitosan nanospheres under microscope $40 \mathrm{X}$

Figure 1: Morphological view of nanospheres. 


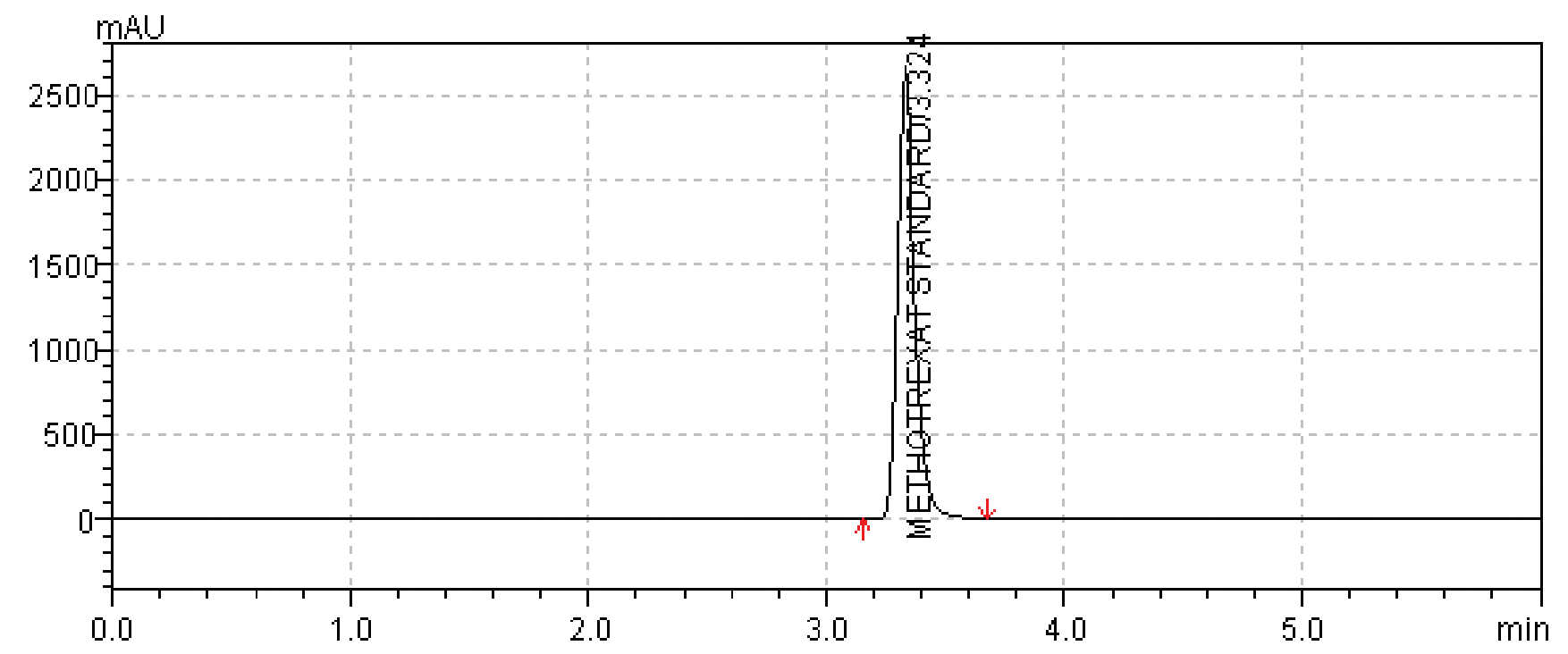

Figure 2: Typical chromatogram of methotrexate standard.

\section{Estimation of amount of drug incorporated}

Estimation of amount of drug incorporated can be done by digesting $10 \mathrm{mg}$ methotrexate drug filled nanosphere (Batch $\mathrm{A}, \mathrm{B}, \mathrm{C}$ ) in 1:1 ratio of $0.1 \mathrm{~N}$ Hydrochloric acid and ethanol. The sample collected was centrifuged at $5300 \mathrm{rpm}$ for 20 minutes. After centrifugation, solution was analysed for the amount of the drug present using HPLC at 480 $\mathrm{nm}^{12-15}$ with the help of standard curve prepared previously (Table 2).

\section{In-vitro drug release studies}

$2.5 \mathrm{mg} / \mathrm{ml}, 5 \mathrm{mg} / \mathrm{ml}, 10 \mathrm{mg} / \mathrm{ml}$ (Batch A, B, C) of drug loaded nanospheres were taken and $100 \mathrm{ml}$ of deionized water $(\mathrm{pH}$ 7-7.4) was added into each of the conical flask. The flasks were kept in an incubator shaker at $37^{\circ} \mathrm{C} \pm 0.5^{\circ} \mathrm{C}$ using 150 revolution/min for a span of 48 hours. $2 \mathrm{ml}$

\begin{tabular}{|c|c|}
\hline Concentration (ng/ml) & Peak Area \\
\hline 200 & 517382 \\
\hline 400 & 1034764 \\
\hline 600 & 1452146 \\
\hline 800 & 2069528 \\
\hline 1000 & 2486910 \\
\hline 1500 & 3880365 \\
\hline
\end{tabular}

of releasing solution was removed as samples at various time intervals and $1 \mathrm{ml}$ of releasing solution taken was then replaced with $2 \mathrm{ml}$ of deionized water immediately. The $2 \mathrm{ml}$ of releasing solution collected was passed through $0.45 \mu \mathrm{m}$ nylon membrane filter to be filtered. Drug content was estimated spectrophotometrically using HPLC at $307 \mathrm{~nm}$.

\section{RESULTS AND DISCUSSION}

Chitosan is a modified natural carbohydrate polymer which issoluble in most organic acidic solutions at $\mathrm{pH}$ less than 6.5 including formic, acetic, tartaric, and citric acid. By simple covalent modifications of the polymer, its physicochemical properties can be changed and can be made suitable for drug delivery purpose. Ionic interactions between positively charged amino groups in chitosan and the negatively charged mucus gel layer make it mucoadhesive. The favourable properties like biocompatibility, biodegradability, $\mathrm{pH}$ sensitiveness, and mucoadhesiveness have enabled chitosan to be chosen to be used as a polymer for nanoparticles.

The major goals in designing nanoparticles as a delivery system are to control particle size, surface properties and release of pharmacologically active agents in order to achieve the site specificaction of the drug at the therapeutically optimal rate and dose regimen. Nanospheres were prepared by modified spontaneous emulsification method which is water in oil emulsion type. First, chitosan was dissolved in glacial acetic acid to form an aqueous phase. After incorporating the drug into the system, linseed oil was added together with acetone into chitosan gel with drug mixture. It was allowed to emulsify under magnetic stirring.

Table 2: Data for percentage drug loading in each batch of nanosphere

\begin{tabular}{ccccccc}
\hline Sample & $\begin{array}{c}\text { Total } \\
\text { Weight } \\
(\mathrm{mg})\end{array}$ & Peak Area & Concentration $(\mu \mathrm{g} / \mathrm{ml})$ & $\begin{array}{c}\text { Practical } \\
\text { Loading }(\mathrm{mg})\end{array}$ & $\begin{array}{c}\text { Theoretical } \\
\text { Loading }(\mathrm{mg})\end{array}$ & $\begin{array}{c}\text { \% Drug } \\
\text { Loading }\end{array}$ \\
\hline $\mathrm{A}$ & 200 & 22733902 & 8.8657 & 0.08866 & 0.125 & 70.93 \\
$\left(\begin{array}{c}2.5 \mathrm{mg}) \\
\mathrm{B}\end{array}\right.$ & 200 & 53021365 & 20.6691 & 0.20669 & 0.250 & 82.68 \\
$(5.0 \mathrm{mg})$ & & & & 0.38495 & 0.500 & 76.81 \\
$\mathrm{C}$ & 200 & 98531430 & 38.4049 & & & \\
$(10.0 \mathrm{mg})$ & & & & & & \\
\hline
\end{tabular}


Table 3: In vitro percentage release of methotrexate from sample A, B and C of nanosphere

\begin{tabular}{|c|c|c|c|c|c|c|c|c|c|}
\hline \multirow{2}{*}{ Formulation } & \multirow{2}{*}{$\begin{array}{l}\text { Time } \\
\text { (hrs) }\end{array}$} & \multirow{2}{*}{ Peak Area } & \multicolumn{2}{|c|}{ Concentration } & \multirow{2}{*}{$\begin{array}{c}\text { Amount } \\
\text { of drug } \\
\text { released } \\
(\mathrm{mg})\end{array}$} & \multirow{2}{*}{$\begin{array}{l}\text { Cumulative } \\
\text { amount of drug } \\
\text { released (mg) }\end{array}$} & \multirow{2}{*}{$\begin{array}{c}\text { Label } \\
\text { claim }(\mathrm{mg})\end{array}$} & \multirow{2}{*}{$\begin{array}{l}\% \text { Drug } \\
\text { released at } \\
\text { each time } \\
\text { interval }\end{array}$} & \multirow{2}{*}{$\begin{array}{l}\text { Cumulative\% } \\
\text { drug releasec }\end{array}$} \\
\hline & & & $\mathrm{ng} / \mathrm{ml}$ & $\mathrm{mg} / \mathrm{ml}$ & & & & & \\
\hline \multirow{8}{*}{ Sample A } & 0 & 0 & 0 & 0 & 0 & 0 & 0 & 0 & 0 \\
\hline & 1 & 750923 & 298.721 & 0.00030 & 0.02987 & 0.0299 & 0.2217 & 13.48 & 13.48 \\
\hline & 2 & 993207 & 393.142 & 0.00039 & 0.03931 & 0.0692 & 0.2217 & 4.26 & 17.74 \\
\hline & 3 & 1357632 & 535.163 & 0.00054 & 0.05352 & 0.1227 & 0.2217 & 6.40 & 24.14 \\
\hline & 6 & 3151784 & 1234.365 & 0.00123 & 0.12344 & 0.4345 & 0.2217 & 7.04 & 55.69 \\
\hline & 12 & 3958631 & 1548.802 & 0.00155 & 0.15488 & 0.7245 & 0.2217 & 8.91 & 69.88 \\
\hline & 24 & 4154972 & 1625.319 & 0.00163 & 0.16253 & 0.8870 & 0.2217 & 3.45 & 73.33 \\
\hline & 48 & 4650762 & 1818.534 & 0.00182 & 0.18185 & 1.4092 & 0.2217 & 3.53 & 82.05 \\
\hline \multirow{8}{*}{ Sample B } & 0 & 0 & 0 & 0 & 0 & 0 & 0.5168 & 0 & 0 \\
\hline & 1 & 1572425 & 618.87 & 0.00062 & 0.0619 & 0.0619 & 0.5168 & 11.98 & 11.98 \\
\hline & 2 & 2010256 & 789.5 & 0.00079 & 0.0789 & 0.1408 & 0.5168 & 3.30 & 15.28 \\
\hline & 3 & 3365321 & 1317.58 & 0.00132 & 0.1318 & 0.2726 & 0.5168 & 10.22 & 25.50 \\
\hline & 6 & 6801963 & 2656.88 & 0.00266 & 0.2657 & 0.9616 & 0.5168 & 6.45 & 51.41 \\
\hline & 12 & 9142013 & 3568.83 & 0.00357 & 0.3569 & 1.6298 & 0.5168 & 8.82 & 69.06 \\
\hline & 24 & 9701362 & 3786.81 & 0.00379 & 0.3787 & 2.0085 & 0.5168 & 4.21 & 73.27 \\
\hline & 48 & 11213095 & 4375.95 & 0.00438 & 0.4376 & 3.2704 & 0.5168 & 1.47 & 84.67 \\
\hline \multirow{8}{*}{ Sample C } & 0 & 0 & 0 & 0 & 0 & 0 & 0.9600 & 0 & 0 \\
\hline & 1 & 2518631 & 987.62 & 0.00099 & 0.0988 & 0.0988 & 0.9600 & 10.29 & 10.29 \\
\hline & 2 & 3314137 & 1297.64 & 0.00130 & 0.1298 & 0.2286 & 0.9600 & 3.23 & 13.52 \\
\hline & 3 & 4910389 & 1919.71 & 0.00192 & 0.1920 & 0.4206 & 0.9600 & 6.47 & 20.00 \\
\hline & 6 & 9817320 & 3832.00 & 0.00383 & 0.3832 & 1.4529 & 0.9600 & 4.48 & 39.92 \\
\hline & 12 & 15115606 & 5896.81 & 0.00590 & 0.5897 & 2.5544 & 0.9600 & 8.12 & 61.43 \\
\hline & 24 & 16117301 & 6287.18 & 0.00629 & 0.6287 & 3.1831 & 0.9600 & 4.06 & 65.49 \\
\hline & 48 & 18513862 & 7221.15 & 0.00722 & 0.7221 & 5.3102 & 0.9600 & 1.23 & 75.22 \\
\hline
\end{tabular}

Table 4: Particle size and zeta potential

\begin{tabular}{ccc}
\hline Sample & $\begin{array}{c}\text { Particle size } \\
(\mathrm{nm})\end{array}$ & $\begin{array}{c}\text { Zeta potential } \\
(\mathrm{mV})\end{array}$ \\
\hline A & 3079.0 & 23.3 \\
B & 2657.0 & -26.5 \\
C & 779.9 & -16.8 \\
\hline
\end{tabular}

Prepared GST with span 80 was added into the mixture and it was allowed to precipitate by the evaporation of acetone to form nanospheres. Toluene was then used to remove remaining oil substance in the emulsion. Then acetone was used to remove the toluene and to dry the resulting substance to prevent aggregation.

Some modifications were done in improving the formulation of nanospheres. $150 \mathrm{cps}$ chitosan was found to be better in the production of uniform and higher amount of nanospheres compared to 27 cps chitosan. $14 \mathrm{ml}$ glutaraldehyde instead of $7 \mathrm{ml}$ glutaraldehyde was used to form GST due to stronger cross linking and hardening of spherical particles. For better dispersion and less clumping of nanospheres, Span 80 in liquid form was utilized. In addition, the ingredients were added dropwise to ensure uniform mixing and further reduce the occurrence of aggregation. Frequency of washing with toluene was increased to maximize the removal of oil content before the washing of nanospheres with acetone. In the estimation of amount of drug incorporated, thethree batches of drug filled nanospheres were digested with the ratio of $1: 1$ of $0.1 \mathrm{~N}$ Hydrochloric acid and ethanol.

Three batches of nanospheres were prepared with the incorporation of $2.5 \mathrm{mg}$ (batch A), $5.0 \mathrm{mg}$ (batch B) and $10.0 \mathrm{mg}$ (batch C) of methotrexate respectively.

The three samples A, B and C prepared from 2.5, 5.0 and $10.0 \mathrm{mg}$ of methotrexate respectively have shown percentage drug loading as summarized in Table 2. An increase the drug concentration using different amounts of drug in the formulation $(2.5 \mathrm{mg}, 5.0 \mathrm{mg}$ and $10.0 \mathrm{mg})$ has shown that it does not depend on the drug payload. In other words, an increase in the drug-to-polymer ratio during formulation does not depend on the concentration of the drug in the nanospheres.

In vitro drug release has shown that $50 \%$ drug release was seen at $5^{\text {th }}$ $6^{\text {th }}$ hour in sample A and B, and $6^{\text {th }}-7^{\text {th }}$ hour for sample C. The concentration of drug in sample A < sample B < sample C. As shown by the in vitro release (Table 3 ), the release pattern of the three samples closely resembles each other. A biphasic release was demonstrated in sample A, $\mathrm{B}$ and $\mathrm{C}$ by the initial burst release at $1^{\text {st }}$ and $8^{\text {th }}$ hour, followed by a stable, plateau release in the subsequent hours (up to hours). The release pattern of the drug from nanospheres is of satisfaction as per the objective of the formulation. This is because the initial burst release could achieve a therapeutic concentration of the drug at the tumor site, and the sustainedrelease phase could provide a constant concentration for the therapeutic effect in the subsequent hours. 
The nanoparticles size was very crucial parameter in determining the saturation solubility, resistance of settling and adhesion of drug particles incorporated to biological surfaces. Sample C, having the $779.9 \mathrm{~nm}$ (Table 4) was said to have the highest saturation solubility, rapid dissolution, resistance to settling. Therefore, its adhesion to biological surfaces is more, thus providing rapid onset of therapeutic action and improved bioavailability. In such case, the drug dose required to achieve the therapeutic benefit is reduced. Due to the potentially high chance of aggregation in nanoparticles, a surfactant, Span 80 was added in the preparation of three formulations.

Sample A $(2.5 \mathrm{mg}), \mathrm{B}(5.0 \mathrm{mg})$ and C (10.0 mg) showed the particle size of $3079 \mathrm{~nm}, 2657 \mathrm{~nm}$, and $779.9 \mathrm{~nm}$ respectively. It indicates that the particle size decrease with increase in concentration of polymer (Table 4). The particle size data showed that the nanoparticle has submicron size and low polydispersity, which indicates relatively narrow size distribution.

Zeta potential is an essential factor to evaluate the stability of nanodispersion. Zeta potential values mainly reflect the electrical repulsion between the particles. The average zeta potential value of methotrexateloaded nanospheres was in the range of $-16.8 \mathrm{mV}$ to $23.3 \mathrm{mV}$. An apparent shift in zeta-potential values to less negative values, which was accompanied by an increase in the particle size.

\section{CONCLUSION}

Targeted drug delivery system using methotrexate-loaded chitosan nanospheres has been designed to deliver drug moiety to a specific site of action. The goal of this formulation is to increase the amount of drug reaching the site of action, reducing its action on neighbouring tissue, thus improving the therapeutic efficiency and minimizing toxic effects. The three batches of methotrexate-loaded nanospheres were formulated by emulsion polymerization method adopting chitosan polymer with good biodegradability as the drug carrier for this formulation. The formulation C (10.0 mg) showed the least particle size, optimum zeta potential range, moderate drug loading efficiency followed by sustained drug release over 48 hours. Hence, this formulation may satisfactorily maintain the bioavailability and targeting efficiency towards cancer cell.

\section{ACKNOWLEDGEMENT}

Author would like to thank AIMST University provided the facilities.

\section{CONFLICT OF INTEREST}

The author have no conflict of interest.

\section{ABBREVIATIONS USED}

None.

\section{ABOUT AUTHOR}

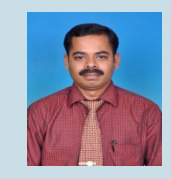

Dr. S. Muralidharan: Has been completed M.Pharm and Ph.D in the Department of Pharmaceutical Analysis in Dr. M.G.R. Medical university, India. Presently working as a senior lecturer in Asian Institute of medicine Science and Technology University (AIMST), Malaysia.

\section{REFERENCES}

1. Majeti NV, Kumar R. Nano and microparticles as controlled drug delivery devices. J Pharm Sci. 2000;3(2):234-58.

2. Mohanraj VJ, ChenY. Nanoparticles - a Review. Trop J Pharm Res. 2006;5(1):561-73.

3. Allemann E, Gurny R, Doelker E. Drug-loaded nanoparticles-preparation methods and drugtargeting issues. Eur J Pharm Biopharm. 1993;39(5):173-91.

4. Couvreur $P$, Vauthier C. Nanotechnology: intelligent design to treat complex disease. Pharm Res. 2006;23(7):284-8

5. The Internet drug Index (2007). Drug Description of Trexall(Methotrexate). Availalbe in http://www.rxlist.com/trexall-drug.htmMedscape [Last accessed on $03 / 07 / 16]$.

6. The Drug Information Handbook. 23 ${ }^{\text {rd }}$ Edition (2014).

7. Gupta M, Sharma V. Targeted drug delivery system: A Review. Res J Chem Sci. $2011 ; 1(2) 143-7$.

8. Prabaharan M, Mano JF. Chitosan-Based Particles as Controlled Drug Delivery Systems. Drug Delivery. 2005;12(1):41-57.
9. National Nanotechnology Initiative (2015) What's So Special about the Nanoscale. Availalbe in http://www.nano.gov/nanotech-101/special [Last accessed on 03/07/16].

10. Wim H De Jong, Paul JA Borm. Drug delivery and nanoparticles: Applications and hazards. Int J Nanomedicine. 2008;3(2):133-49.

11. Grenha A. Chitosan Nanoparticles: survey of preparation methods. J Drug Targeting. 2012;7-38.

12. Skoog DA. Analytical Chemistry, $7^{\text {th }}$ Edition, Saunders College Publishers, Philadelphia, 1996, 1-15.

13. Brain WW, Cooper D. Samples and standards, Analytical Chemistry by Open Learning, John Wiley and Sons, London, 1991, 2-5.

14. Braun RD. Introduction to Instrumental Analysis. $1^{\text {st }}$ edn, McGraw Hill Book Company, 1987, 1-13.

15. Jeffery GH, Basselt J. Vogel's Text Book of Quantitative Chemical Analysis. $5^{\text {th }}$ ed, 1991, 217-35. 